\title{
Raúl Prebisch: Los años de gobierno
}

Roberto Cortés Conde*

\section{Los primeros años}

El Prebisch que hoy la mayor parte de la gente recuerda tuvo una destacadísima actuación en los ámbitos internacionales con esporádicas intervenciones (1955 y 1984) en el quehacer económico argentino; ese Prebisch que vivió la segunda mitad del siglo XX fuera de la Argentina tuvo, sin embargo, en sus años jóvenes, un papel importantísimo en el diseño e implementación de políticas que produjeron cambios notables en el país.

Había egresado de la Facultad de Ciencias Económicas en 1923 y veinte años más tarde, con sólo 42, concluía forzadamente su actuación como gerente del Banco Central de la República Argentina, tras ocho años de gestión y de haber pasado por altas funciones de gobierno.

Siendo todavía estudiante tradujo el estudio que J.H.Williams presentara en los seminarios de la facultad. ${ }^{1}$ Ese trabajo y, por su intermedio, las ideas de Taussig sobre los ciclos económicos y ajustes del balance de pagos con movimiento de capitales le sugirieron la idea de analizar los ciclos argentinos y los

\footnotetext{
* Departamento de Economía de la Universidad de San Andrés, Buenos Aires (cortes@udesa.edu.ar). Esta es una versión editada de la exposición que hiciera el autor en la sede de la CEPAL, en Santiago, el 17 de abril de 2001, con motivo del natalicio de Raúl Prebisch.

1 Véase Williams, 1969.
}

mecanismos no previstos en la teoría corriente sobre comercio internacional.

En 1922 Alejandro Bunge lo propuso como Director de Estadística de la Sociedad Rural Argentina. Allí encabezó un equipo que en 1928 publicó un Anuario con la más completa reseña estadístico-histórica del país.

Ese mismo año, se le encomendó la organización de una oficina de investigaciones económicas en el Banco de la Nación Argentina, institución donde realizó una importante tarea de información estadística y análisis de coyuntura económica que quedó reflejada en la Revista económica que publicaba el Banco (BNA, 1928).

Cuando la Argentina se encontró frente a nuevos problemas en la década de 1930 los conocimientos teóricos y estadísticos adquiridos le permitieron hacer frente a un desafío al que pocos intelectuales en el país han podido responder. Las circunstancias que le tocaron vivir —el fin de un mundo, el de la belle époquey la aparición de otro nuevo, el de las economías cerradas y las reacciones nacionalistas, fueron para todos difícil de entender.

Había que adecuar o construir teorías que explicaran fenómenos previamente desconocidos y por lo tanto no estudiados. Su paso por Australia en los años veinte, su estada en los Estados Unidos — su misma amistad con Williams-, lo ayudaron en esa tarea y le permitieron estar al tanto de los desarrollos intelectuales más recientes. 
Bajo la influencia del estudio de Williams sobre los mecanismos de ajuste del balance de pagos, en un país con papel moneda inconvertible y de las teorías del ciclo económico (Taussig, 1915; Hawtrey, 1919; Kondratieff, 1946), comenzó a elaborar nuevas interpretaciones sobre las características del ciclo argentino. Argentina tenía una economía que dependía de sus exportaciones de cereales y esto le daba una característica estacional y a la vez la hacía muy vulnerable, ya que estaba afectada por circunstancias meteorológicas y por las grandes fluctuaciones de los mercados externos. Además existía un mecanismo monetario que acentuaba tales fluctuaciones. El ciclo estacional —al que se había dado en llamar el ciclo argentino- se traducía en que al liquidarse las cosechas en los meses de verano entraba oro y los bancos expandían el crédito, mientras que en el invierno, cuando no entraban saldos exportables, se producía una retracción y los bancos contraían el crédito. De allí surgió la idea de las acciones contracíclicas.

En 1921, siendo todavía alumno de la Facultad de Ciencias Económicas, Prebisch publicó las "Notas para la historia monetaria de la Argentina” (Prebisch, 1921), en las que se remontó a los antecedentes monetarios coloniales, advirtiendo la paradoja de que en esta colonia productora de plata escaseaba el circulante. No es que faltara plata — decía—, sino que como la casa de acuñación recibía la moneda a un precio inferior al que tenía como mercancía, ella se atesoraba y sólo circulaba la moneda mala: la macuquina, una moneda feble y despreciada porque tenía menor contenido metálico, o los sustitutos en moneda de la tierra (Ley de Gresham). Allí estudió la experiencia de los bancos de emisión y el del papel moneda inconvertible. También las crisis de 1876, 1885 y 1890, sosteniendo que fueron el resultado de una sobreexpansión del crédito en las fases ascendentes del ciclo en las que se creó poder adquisitivo por medio de la emisión; esta situación se revirtió cuando apareció un déficit en el balance de pagos y se tuvo que contraer la oferta monetaria. En la parte final del citado artículo se ocupó de la crisis de 1913 y comenzó a esbozar una teoría sobre las perturbaciones monetarias en las fases cíclicas con régimen de Caja de Conversión, que desarrollaría más adelante desde el Banco Central, en la Memoria de 1938 de la institución (BCRA,1939). Al respecto dice que mientras en los bancos de emisión ésta se hace sobre la base del crédito comercial, en la Caja de Conversión sólo se puede hacer con el excedente del balance de pagos (reservas en oro). Pero advierte que incluso en este régimen las entradas de oro producen no sólo un aumento del circulante sino también de las reservas de los bancos, los que al tener más reservas expanden el crédito. Luego, en una fase ascendente del ciclo se produce una sobreexpansión del crédito (tendencia procíclica), mientras que cuando ocurre lo contrario sale el oro, disminuyen las reservas y se contrae aun más el crédito. Esto ocurrió — - según él—en 1913 en la fase descendente del ciclo, provocando una reacción en cadena y dando origen a un general pesimismo sobre las perspectivas de la economía, que acentuó la recesión por sus efectos sobre el consumo y la inversión.

\section{Los años de gobierno y del Banco Central}

Los años treinta fueron de enormes dificultades, pero también de nuevas experiencias en la formulación y puesta en práctica de políticas económicas en los nuevos roles que asumió el gobierno.

La crisis mundial de 1930 exigió ubicarse en un contexto internacional distinto y encontrar respuestas a situaciones que no eran conocidas.

En 1933 Prebisch había leído los cuatro artículos de Keynes publicados en The Times, a partir de los cuales, dijo, "empecé a pensar en una política expansiva". ${ }^{2}$ Más adelante difundiría en castellano las ideas keynesianas (Prebisch, 1947).

Tras las enormes perturbaciones en los mercados internacionales de mercancías y capitales en el período posterior a la Primera Guerra Mundial se había advertido la rigidez del patrón oro. Argentina había sido uno de los pocos países que, siguiendo a Gran Bretaña, volvió a abrir la Caja de Conversión en 1927, a la antigua paridad de preguerra. Debe decirse que durante los años en que dicha Caja había estado cerrada la emisión se había seguido haciendo bajo las reglas del patrón oro. En 1914 se había dictado una ley que permitió la creación de dinero sobre la base de descuentos de documentos del Banco de la Nación Argentina, siempre que se mantuviera un $40 \%$ de reservas en oro. Esta facultad, sin embargo, no había sido usada. En 1929, tras la caída de la Bolsa de Nueva York y temiendo una corrida, el gobierno decidió cerrar la Caja de Conversión, pero no impidió las remesas al exterior y, tras la primera devaluación, trató de mantener un tipo de cambio sobrevaluado respecto del peso mediante la venta de oro. Tras la revolución de 1930 y en una difícil situación, pues continuaba la salida de

\footnotetext{
2 Citado en Fernández López, 1996.
} 
oro para pagar deudas e importaciones y se acumulaban atrasos en la entrega de divisas, se decidió - siguiendo la ley de 1914- que la Caja emitiera sobre la base de documentos descontados por el Banco de la Nación Argentina. Como advirtió el mismo Prebisch -que había ocupado la Subsecretaría de Hacienda hasta 1932 - esta medida no marcaba todavía un cambio en la política ortodoxa con la que el gobierno pretendía afrontar la crisis (es decir, la de reducir gastos y aumentar impuestos), sino que se tomó frente a la necesidad de reponer los efectivos del sistema bancario que con la salida de oro habían quedado exhaustos. De todos modos se flexibilizó el régimen de patrón oro. Se crearon los impuestos a los réditos y se redujeron los gastos del gobierno, bajando las remuneraciones de los empleados públicos. Más que con el cierre de la Caja de Conversión y la aplicación de la ley de 1914, fue en 1932 cuando se emitió sobre la base de títulos públicos para financiar el déficit de Tesorería y se pasó a una nueva concepción del régimen monetario.

En 1933, con la entrada de Pinedo en el gabinete como ministro de Hacienda y la vuelta de Prebisch como subsecretario, se pusieron en práctica medidas que fueron parte de un plan orientado por una nueva concepción de políticas económicas. A pedido de los ministros Pinedo y Duhau se elaboraron ciertas medidas económicas que se reflejaron en el Plan de Acción Económica Nacional de noviembre de 1933.

En ese año se devaluó el peso con el propósito de equilibrar el balance de pagos, pero también para apoyar al agro. Hubo — dice Prebisch - una verdadera redistribución de utilidades; no se trató solamente de una mera medida de cambios, sino que se la combinó con la de comprar los saldos invendibles de las cosechas, para dar a la población un mayor poder adquisitivo. También se pensó con ello estimular la actividad económica, con la construcción de obras públicas y la ayuda a la industria.

Asimismo, se estableció el control de cambios con dos mercados; uno oficial, en el cual se liquidaban las divisas sobre los precios aforados de las exportaciones regulares, y otro libre, en el que se permitía la venta del excedente sobre los aforos y las exportaciones no tradicionales a los países vecinos. Se establecieron dos tipos de cambio: uno comprador a 15 pesos por libra, y otro vendedor, donde ésta quedó finalmente a 17 pesos. Como a esos tipos de cambio la demanda de divisas fue mayor que su oferta, se estableció su racionamiento mediante permisos previos de importación, con criterios decididos por el gobierno. Según dijo Prebisch, "Por primera vez se pone en juego un plan de carácter monetario y financiero que se substrae a las viejas influencias clásicas" (BCRA, 1986, p. 50).

Todos entendían que esas medidas eran extraordinarias, como lo eran los hechos que trataban de corregir, y que cuando se creó el Banco Central en 1935 y se dejó subsistir el control de cambios existía, sin embargo, el ánimo de desembarazarse de él y volver a un mercado libre. En el mensaje que acompañó el proyecto de establecer dicho banco - anotaba Prebischse advierte que el propósito fue crear un banco que mantuviera el valor de la moneda y que permitiera retornar a la normalidad monetaria, pero siempre que lo hicieran las principales naciones del mundo y se hubiera restablecido el comercio internacional. Pero "si prevalece el régimen de economías cerradas - agregaba el mensaje- el país tendrá en el Banco Central el medio de adaptar su política a esta situación de hecho, en defensa de los intereses nacionales" (BCRA, 1986, p. 51). Esas medidas se adoptaron entonces en respuesta al cierre de las economías en los países más desarrollados.

\section{El Banco Central}

Prebisch integró la primera comisión redactora de un proyecto de banco central, que fue desechado para recabarse otro de Otto Niemeyer, quien ya había preparado uno similar para Brasil. La ley de 1935, sin embargo, difería del proyecto Niemeyer e incorporaba modificaciones que llevaban la impronta de Prebisch.

La creación del Banco Central tuvo como objetivo lograr la estabilidad monetaria y atenuar las perturbaciones del ciclo económico. Sostenía Prebisch que dadas las características del ciclo en la Argentina el Banco Central debía intervenir para atenuar las fluctuaciones, utilizando para ello instrumentos de absorción. En cambio — según él—, el redescuento tendría sólo una función transitoria.

"De manera que si bien el Banco es de corte clásico... la realidad no le iba a permitir actuar de esa forma" y se debería admitir "la posibilidad de aplicar otro género de política". Aquí reiteraba los conceptos ya adelantados al comienzo de los años treinta en "La acción de emergencia en el problema monetario" (Prebisch, 1991, p. 51). Y sigue, "Dentro del régimen estricto del patrón oro había una falla intrínseca en el sistema, a saber: durante el período ascendente crecen los efectivos de los bancos y esto los induce a prestar más dinero, por el juego natural de la competencia entre ellos, a crear mayor cantidad de poder adquisitivo 
de la que se obtiene en virtud del balance de pagos. Esta creación de poder adquisitivo agranda los efectos de la fase ascendente y obliga a una contracción más violenta en la fase descendente. Pero no se lo hace creando dinero sino aumentando los encajes de los bancos durante la fase ascendente, recogiendo el efectivo adicional y esterilizándolo para que no pueda servir a la expansión del crédito y luego cuando la situación se invierte devolverlo para evitar una contracción" (Ibid., p. 52).

El redescuento se utilizaría sólo con funciones limitadas cuando fracasaba una cosecha o se reducía la exportación y se exportaba metálico. En esas circunstancias convenía el redescuento para aliviar la plaza y para que no se contrajera la actividad agropecuaria y todas las demás vinculadas a ellas.

La primera intervención del Banco Central se llevó a cabo desde 1935 hasta mediados de 1937, en la fase ascendente, creándose los certificados de participación que permitieron esterilizar capacidad adquisitiva (ahorro), además de recomprarse parte de la deuda externa en dólares. Cuando se advirtió, a mediados de 1937, que el ciclo se revertía y comenzaba una fase descendente, se usaron las reservas y se devolvió la capacidad adquisitiva al público para evitar que se generalizara una recesión. Se quiso suavizar la curva cíclica, lo que fue la segunda etapa — decía Prebischde "nuestras ideas monetarias". Hasta aquí en la fase ascendente se retiraba poder adquisitivo que se devolvía en la descendente, pero no se creaba dinero.

En la siguiente intervención, durante los primeros años de la Segunda Guerra Mundial, se fue mucho más lejos. Frente a la fuerte contracción de los primeros tiempos de la guerra, cuando desaparecieron los mercados tradicionales, se quiso dar un papel más activo a la política de regulación de medios de pago, creando poder adquisitivo para impulsar la industria y las construcciones; es decir, se preconizó una política muy activa en el mercado para lograr el desarrollo de la economía, pero siempre dentro de un circuito monetario controlado mediante el régimen de control de cambios.

Esta idea había sido el centro de la propuesta del ministro Pinedo en su Plan de Reactivación Económica de 1940 (BCRA, 1986), que consistía en movilizar una enorme cantidad de depósitos ociosos colocados a corto plazo en el sistema financiero, para que con la intervención del Banco Central - que los compraría- se posibilitara que los bancos comerciales prestaran a largo plazo para impulsar principalmente la construcción (que era para Prebisch el motor más dinámico) y la industria local. Esto debía hacerse con extrema prudencia y mientras no se llegara al pleno empleo de los factores de producción, porque de lo contrario se recaería en procesos inflacionarios.

Estas medidas — dijo Prebisch - finalmente resultaron innecesarias, ya que a partir de 1941, con la entrada de los Estados Unidos al conflicto, subieron las exportaciones, se restringió la oferta de importaciones y se elevó la capacidad adquisitiva en el país. Sin embargo, este instrumento sería usado en muy distintas circunstancias con consecuencias altamente inflacionarias, lo que criticó en su informe de 1955 al gobierno argentino (BCRA, 1956).

\section{Conclusiones}

En sus años en funciones de gobierno Prebisch tuvo una actuación principal en la elaboración de nuevas ideas y políticas económicas, las que tuvieron una profunda influencia en los decenios siguientes. Muchas de ellas se propusieron como respuestas a circunstancias excepcionales y debían abandonarse si aquéllas desaparecían y, por ende, fueron respuestas a un mundo en que las economías se habían cerrado y no había mercados internacionales de capitales.

El punto de partida fue el convencimiento de que el patrón oro podía evitar crisis monetarias, pero no podía evitar las crisis bancarias, lo que tenía graves consecuencia sobre toda la economía debido al carácter procíclico del crédito bancario. Prebisch propuso que los encajes debían aumentar en la fase de expansión y disminuir en la de contracción, debiendo establecerse un Fondo de Reserva que retirara poder de compra (con certificados de absorción) del público y lo devolviera (comprando esos bonos) en la fase de declinación, mientras que el redescuento debía ser sólo transitorio. Para que ese poder de compra no se desviara a las importaciones debía existir un régimen de control de cambios con permisos de cambio selectivos.

Finalmente - aunque Prebisch no lo dice- las políticas anticíclicas deben aplicarse en la fase ascendente, cuando es posible acumular reservas. Si en la descendente no se puede retirar poder de compra, sólo se podría expandir creando dinero, lo que él no recomienda, ya que produciría inflación. Pero todo esto requiere - y éste es un aspecto que Prebisch no menciona por obvio - un Estado solvente y con credibilidad.

En realidad esto es algo similar al suavizamiento (smoothing) de los impuestos. Pero ¿por qué usar el instrumento monetario en vez del fiscal? El instrumen- 
to fiscal no estuvo descartado, ya que en la fase ascendente de 1935-1937 se procedió a la recompra de deuda externa con parte del superávit; sin embargo, al parecer fue políticamente más fácil restringir el crédito, aumentando las reservas, en una fase ascendente que elevar impuestos o reducir gastos cuando esto ya se había hecho previamente para equilibrar el presupuesto.

Finalmente, la última etapa de lo que Prebisch llamó el pensamiento de la gestión económica tiene que ver con el plan de reactivación del ministro Pinedo y las políticas del Banco Central encaminadas a usar un excedente de depósitos ociosos de corto plazo en préstamos a largo plazo y promover la actividad de la construcción y de las industrias. El Banco Central tomaría esos depósitos a corto plazo y los prestaría luego a los bancos a largo plazo. La justificación de la medida era el trastorno que había causado la guerra en la produc- ción agropecuaria, que no encontraba salida, y la necesidad de orientarse al mercado interno. La entrada de Estados Unidos al conflicto bélico en 1941 cambió la situación, ya que aumentaron las exportaciones a ese país de lanas y cueros y disminuyeron las importaciones, lo que llevó al equilibrio del balance de pagos y, según Prebisch, hizo innecesaria su aplicación.

De todos modos, sí se habían creado nuevos instrumentos de política.

Después de que se dejó a Prebisch fuera del Banco Central, en 1943, la institución generalizó el uso reiterado de redescuentos, lo que tuvo consecuencias muy adversas para la economía, como él mismo subrayara en su informe de 1955 al gobierno argentino (BCRA,1956). Ya entonces, tras más de una década en el gobierno, sus ideas económicas habían madurado. Ellas tuvieron influencias innegables en el pensamiento y en la historia económica de la Argentina.

Bibliografía

BCRA (Banco Central de la República Argentina) (1939): Memoria anual del Banco Central, 1938, Buenos Aires.

(1956): Memoria Anual del Banco Central,1955, apéndice I, Buenos Aires.

(1986): 1935-1985 Cincuentenario del Banco Central de la República Argentina, Buenos Aires.

BNA (Banco de la Nación Argentina) (1928): Revista económica, Buenos Aires.

Fernández López, M. (1996): El ciclo económico argentino: estudios de Raúl Prebisch, Revista ciclos, vol. VI, N 10, Buenos Aires, Universidad de Buenos Aires.

Hawtrey, R.G. (1919): Currency and Credit, Londres.

Kondratieff, N.I. (1946): Las ondas largas de la economía, Madrid.
Prebisch, R. (1921): Notas para la historia monetaria de la Argentina, Revista de ciencias económicas, Buenos Aires.

(1947): Introducción a Keynes, México, D.F., Fondo de Cultura Económica.

(1991): La acción de emergencia en el problema monetario, Raúl Prebisch. Obras 1919-1948, tomo II, Buenos Aires, Fundación Raúl Prebisch.

Taussig, F.W. (1915): Principles of Economics, Nueva York, The MacMillan Company.

Williams, J.H. (1969): Argentine International Trade Under Inconvertible Paper Money, 1880-1900, Nueva York, Greenwood Press. 